\title{
Relations Among Reinvestment, Self-Regulation, and Perception of Choking Under Pressure
}

\author{
by \\ Takehiro Iwatsuki ${ }^{1}$, Judy L. Van Raalte², Britton W. Brewer2, Albert Petitpas², \\ Masanori Takahashi ${ }^{3}$
}

The purpose of this study was to examine relations among reinvestment, self-regulation, and perception of choking under pressure in skilled tennis players. Participants were 160 collegiate players from the NCAA Division I in the U.S. and the 1st League in Japan. Participants completed questionnaires assessing reinvestment (conscious motor processing and movement self-consciousness), self-regulation, and perception of choking under pressure. Results of correlation analysis indicated self-regulatory factors were positively related to reinvestment conscious motor processing, but not with reinvestment movement self-consciousness. Self-efficacy and movement self-consciousness of reinvestment were found to predict one's perception of choking under pressure. Results of simultaneous entry multiple regression revealed that tennis players who had low self-efficacy and were concerned about making a good impression with their movements were more likely to perceive that they choked during tennis matches. Additionally, Japanese players reported less self-regulation skills and a higher perception of choking under pressure than American players, suggesting the need for additional research on cross-cultural differences. Overall, these results suggest that self-efficacy may protect athletes from choking, but movement self-consciousness may lead athletes to choke during tennis games.

Key words: self-focus, metacognition, self-efficacy, collegiate athletes, cross-cultural comparison.

\section{Introduction}

Competitive tennis requires excellent fitness and mental focus for optimal performance. Research has shown, however, that even skilled performers sometimes choke under pressure (Beilock, 2010). Beilock defined the term choking under pressure as the worst performance that athletes would expect, given their skill level, in situations where performance pressure is at a maximum. The main key that involves choking is not just a poor/substandard performance, but a player's worst performance.

A number of researchers (e.g., Beilock and Carr, 2001; Jackson et al., 2006; Masters, 1992) have supported a self-focus model where choking is explained by increased self-awareness and selfconsciousness about performing correctly
(Baumeister, 1984). Masters and Maxwell (2008) suggested that trying to perform correctly led athletes to consciously control their behaviour and movement, leading to poor performance. The "conscious processing hypothesis" extended the self-focus model by demonstrating that pressure increases attention to apply explicit rules to control movements (Masters, 1992). Substandard performance resulting from conscious processing is known as reinvestment.

Reinvestment can be defined as the "manipulation of conscious, explicit, rule based knowledge, by working memory, to control the mechanics of one's movements during motor output" (Masters and Maxwell, 2004). Reinvestment theory is predicated on the

1 - Department of Kinesiology, Pennsylvania State University, Altoona College, Altoona, Pennsylvania, USA.

2 - Department of Psychology, Springfield College, Springfield, Massachusett, USA.

3 - Department of Physical Education, Nihon University, Setagaya, Tokyo, Japan. 
perspective that performance can be disrupted if athletes try to control movements consciously with declarative knowledge (Masters and Maxwell, 2008). According to reinvestment theory (Masters and Maxwell, 2008), athletes who internally self-regulate their performance are more likely to control their movements, which leads to a poor performance. Additionally, reinvestment theory suggests that athletes who focus on the mechanical aspects of motor performance are more likely to experience "paralysis by analysis," or choking under pressure, than other athletes (Jackson et al., 2006).

Reinvestment is associated with choking in competition. Self-regulatory behaviours have shown to be closely related to conscious awareness of one's mechanics of performance, increasing one's risk of performance failure (Masters and Maxwell, 2008). Self-regulation, however, has been considered the ability to control thoughts, feelings, and actions, and has been widely examined in psychological research and identified as a crucial factor to sport performance (Nota et al., 2004). Much research has shown that athletes who possess high selfregulation skills perform better than those who possess low self-regulation skills (Cleary and Zimmerman, 2001; Cleary et al., 2006; Jonker et al., 2010; Kitsantas and Zimmerman, 2002; Toering et al., 2009).

In Zimmerman's self-regulation theory, self-regulation is described as the extent to which individuals are metacognitively, motivationally, and behaviourally proactive in their own learning processes (Zimmerman, 2006, 2008). Studies related to the Zimmerman's concept of selfregulation theory have been conducted in various sports. For instance, Toering et al. (2009) studied self-regulation in elite youth soccer players and found them to have higher self-regulation skills (e.g., greater reflection) than their non-elite peers. Jonker et al. (2011) also noted the importance of reflecting on learning based on one's previous experiences. Cleary et al. (2006), Cleary and Zimmerman (2001), and Kitsantas and Zimmerman (2002) examined the use of selfregulation skills in sport. Cleary et al. (2006) found that in men's basketball, elite athletes used more self-regulation skills, such as selfmonitoring and self-efficacy, than both non-elite athletes and novices when practicing free throw shots. This was true with high school basketball players practicing free throws (Cleary and Zimmerman, 2001), as well as volleyball athletes practicing serving (Kitsantas and Zimmerman, 2002). In each of the three studies, there was a positive correlation between performance and self-regulation skills.

Self-regulation behaviours are, therefore, associated not only with reinvestment and performance failure, but also with enhanced performance. Thus, there is an apparent paradox: self-regulation skills are positively associated with sport performance and are possessed and used to a greater extent by elite athletes than non-elite athletes (e.g., Cleary et al., 2006; Cleary and Zimmerman, 2001; Junker at al., 2010, 2011; Kitsantas and Zimmerman, 2002; Toering et al., 2009), but athletes who self-regulate and reinvest on mechanical details during competition are prone to choke or show poor performance (e.g., Masters and Maxwell, 2008; Masters et al., 2005). Masters and Maxwell (2008) suggested that selfregulatory behaviours are associated with consciousness of one's moving/movement (reinvestment), thereby implying that selfregulation and reinvestment may be associated with each other. However, little research has examined the relationships between reinvestment and self-regulation, and no research has focused on tennis players or on a cross-cultural comparison of these factors.

Cultural differences have been identified between American and Asian athletes, in terms of goal orientation (Hayashi and Weiss, 1994), athletic identity (Matheson et al., 1994), and the way self-talk affects performance (Peters and Williams, 2006). For example, Peters and Williams (2006) found that European Americans used more positive self-talk than East Asians, but East Asians used more negative self-talk than European Americans. Also, negative self-talk was related to poor performance for European Americans but good performance for East Asians. Therefore, it is clear that the findings from one population cannot simply be transferred to another population. There are varying cultures and backgrounds to be considered between two different populations.

Regarding the differences between American and Japanese individuals in general, Kitayama (2002) has published his work on various topics. For instance, Americans are more 
independent, whereas Japanese are more interdependent (Kitayama, 2002; Kitayama et al., 2009). Additionally, it was reported that Americans tended to enhance themselves, while Japanese tended to criticize themselves (Kitayama et al., 1997). In regard to the sport related population, Isogai et al. (2003) found that American students had high task orientation goals, whereas Japanese students had high ego orientation goals. There is, however, a limited number of literature that examine cultural differences between Americans and Japanese in sport settings.

Given the examples of cross-cultural differences in sport- and performance- related variables between American and Asian athletes individually, a cross-cultural comparison between American and Japanese tennis players on reinvestment, self-regulation, and the perception of choking under pressure would facilitate a better understanding of these factors across cultures.

To address this issue, as there is an apparent paradox between self-regulation and reinvestment, correlation analysis was used to examine whether self-regulation and reinvestment were related or not. Additionally, simultaneous entry multiple regression analyses were conducted to predict factors related to the perception of choking under pressure. We hypothesized that reinvestment factors would be predictors for one's perception of choking under pressure (e.g., Masters and Maxwell, 2008; Masters et al., 2005). Also, we hypothesized that self-efficacy would be negatively correlated with the perception of choking under pressure because self-efficacy and performance had been found to have a positive relationship (e.g., Feltz and Lirgg, 2001). Consequently, the purpose of this study was to examine relations among reinvestment, self-regulation, and perception of choking under pressure in skilled tennis players, and to compare the differences between American and Japanese athletes.

\section{Methods}

\section{Participants}

Participants were 160 collegiate tennis players (91 males, 69 females) with a mean age of $19.81(S D=1.17)$ years. Fifty-eight American participants (28 males, 30 females) attended the
NCAA Division I school, which was the highest collegiate level in U.S. (followed by Division II and Division III). One hundred-two Japanese participants (63 males, 39 females) were from the League I school, which was the highest collegiate level in Japan (followed by the League 2 to League 7). The amount of tennis experience of participants was $11.37(S D=2.97)$ years.

\section{Instruments}

Movement Specific Reinvestment Scale (MSRS; Masters et al., 2005). The MSRS is a 10item questionnaire that consists of two independent factors: conscious motor processing and movement self-consciousness. Participants completed the 10 items with reference to how they move in their sport on 6-point Likert scales with response options ranging from 1 (strongly disagree) to 6 (strongly agree). Conscious motor processing measures a tendency to consciously control movement, and individuals who score highly on this factor are more likely to monitor and consciously control their movements during motor output. Movement self-consciousness measures a tendency to consciously monitor one's style of movement, and individuals who score high on this factor are more concerned about their style of movement and about making a good impression during motor output.

Planning, self-monitoring, effort, and selfefficacy. Subscales for planning ( 9 items), selfmonitoring (5 items), effort (10 items), and selfefficacy (10 items) were adapted from the work of Hong and O'Neil Jr. (2001). Participants completed a total of 34 items using 4-point Likert scales with response options ranging from 1 (almost never) to 4 (almost always).

Reflection. The Reflective Learning Continuum (RLC, Peltier et al., 2006) is a 5-item scale that was used to assess reflection on thoughts and behaviours. Participants completed the items using 5-point Likert scales with response options ranging from 1 (strongly agree) to 5 (strongly disagree). Low scores on the RLC indicate a high level of reflection skills. For the sake of clarity, RLC scores were reversed for analysis. Therefore, high scores on this subscale mean a high level of reflection skills.

Evaluation. The evaluation subscale of the Inventory of Metacognitive Self-Regulation (IMSR) is an 8-item questionnaire developed by Howard et al. (2000), and was used to examine 
evaluation of thoughts and behaviours. Participants completed the items using 5-point Likert scales, with choices ranging from 1 (never) to 5 (always).

Perception of choking under pressure. The perception of choking under pressure was one's perceived tendency to choke under pressure. Participants completed one item (i.e., "What is your tendency to choke under pressure in tennis matches?") using a 10-point Likert scale from 1 (never choke) to 10 (always choke). Three previous studies (Iwatsuki and Wright, 2016; Study 2 in Kinrade et al., 2010; Study 4 in Masters et al., 1993) measured the players' tendency to choke under pressure using the same 10-point Likert question.

\section{Procedure}

Institutional review board approval was received prior to conducting this study. Participants were asked to read and sign an informed consent form before filling out the questionnaires. Participants completed the MSRS, self-regulation, perceived choking under pressure, and demographic questionnaires.

\section{Statistical analysis}

Pearson correlations were used to examine the relations among the two MSRS factors (i.e., conscious motor processing and movement self-consciousness), six self-regulation factors (planning, self-monitoring, effort, selfefficacy, reflection, and evaluation), and perceived choking. Simultaneous entry multiple regression analyses were conducted to assess the extent to which the MSRS factors and self-regulation factors predicted the perception of choking under pressure among the combined American and Japanese sample, the American subsample, and the Japanese subsample. Additionally, multivariate analysis of variance (MANOVA) was used to explore difference between American and Japanese participants on two MSRS factors, six self-regulation factors, and perceived choking under pressure.

\section{Results}

Correlations among two independent factors of the MSRS, six self-regulation independent factors, and perceived choking are presented in Table 1. Conscious motor processing had significant positive correlations with all six self-regulation factors (i.e., planning, monitoring, effort, self-efficacy, reflection, and evaluation), but was not significantly correlated with perceived choking. In contrast, movement selfconsciousness was significantly correlated with none of the six self-regulation factors, but was significantly correlated with perceived choking. Perceived choking was positively correlated with movement self-consciousness and negatively correlated with planning, monitoring, and selfefficacy.

Simultaneous entry multiple regression analyses were performed to determine if the reinvestment and self-regulation factors predicted perceived choking under pressure among the combined American and Japanese sample, the American subsample, and the Japanese subsample (Table 2). The results of the simultaneous entry multiple regression equation for the combined American and Japanese sample were statistically significant, $(F(8,151)=5.601, p<$ $.001)$, and the predictor variables accounted for $23 \%$ of the variance in the criterion variable. The results indicated that movement selfconsciousness and self-efficacy were significant predictors of perceived choking under pressure. Movement self-consciousness was associated with an increase in perceived choking under pressure $($ Beta $=.17, p<.05)$. Additionally, self-efficacy decreased as perceived choking under pressure decreased $($ Beta $=-.476, p<.001)$.

For the Japanese subsample, the regression equation was statistically significant $(F(8,93)=3.853, p=.001)$, with the predictors accounting for $25 \%$ of the variance in the criterion variable. These results revealed effort and selfefficacy were significant predictors of perceived choking under pressure. Effort was positively associated $(\beta=.29, p<.01)$ with perceived choking under pressure and self-efficacy was negatively associated $(\beta=-.42, p<.001)$ with perceived choking under pressure. The regression equation was not statistically significant for the American subsample.

As shown in Table 3, the results of MANOVA comparing the responses of American and Japanese participants indicated that there were significant differences between American and Japanese participants, Wilks $\lambda, F(9,150)=$ 9.11, $p<.001, n^{2}=.35$. Follow-up ANOVAs to explore differences between American and Japanese participants revealed that, relative to 
Japanese participants, American participants were found to have higher conscious motor processing, $F(1,150)=8.84, p<.01, n^{2}=.05$, planning, $F(1$, $150)=32.71, p<.001, n^{2}=.18$, monitoring, $F(1$, $150)=23.74, p<.001, n^{2}=.13$, effort, $F(1,150)=$ 26.61, $p<.001, n^{2}=.14$, self-efficacy, $F(1,150)=$ $60.13, p<.001, n^{2}=.28$, reflection, $F(1,150)=35.97$, $p<.001, n^{2}=.19$, and evaluation, $F(1,150)=13.77$, $p<.001, n^{2}=.08$. American participants, in contrast, were found to have lower perceived choking under pressure, $F(1,150)=18.27, p<.001$, $n^{2}=.11$, than Japanese participants. Regarding movement self-consciousness, no significant difference existed between American and Japanese participants.

Table 1

Pearson correlations among reinvestment, self-regulation, and perceived choking under pressure

$\begin{array}{lllllllll}9 & 1 & 2 & 3 & 4 & 5 & 6 & 7 & 8\end{array}$

1. Conscious Motor Processing

(Reinvestment)

2. Movement Self-Consciousness $.47^{* * *} \quad$

(Reinvestment)

3. Planning

(Self-Regulation)

4. Monitoring (Self-Regulation)

5. Effort

(Self-Regulation)

6. Self-Efficacy

(Self-Regulation)

7. Reflection

(Self-Regulation)

8. Evaluation

(Self-Regulation)

9. Perceived Choking Under

Pressure

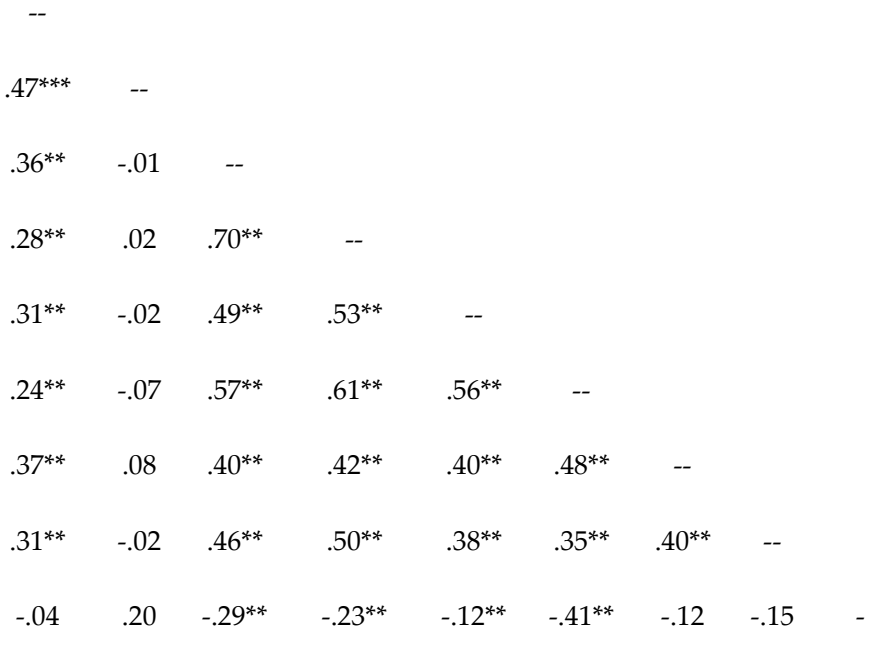

${ }^{*} p<.05,{ }^{* *} p<.01$

\begin{tabular}{|c|c|c|c|c|c|c|c|c|c|}
\hline \multirow{2}{*}{\multicolumn{10}{|c|}{$\begin{array}{l}\text { Table } 2 \\
\text { Summary of simultaneous entry multiple regression analyses of perceived choking under pressure }\end{array}$}} \\
\hline & & & & & & & & & \\
\hline & \multicolumn{3}{|c|}{$\begin{array}{l}\text { Combined American and } \\
\text { Japanese Sample }\end{array}$} & \multicolumn{3}{|c|}{ American subsample } & \multicolumn{3}{|c|}{ Japanese Subsample } \\
\hline & $\mathrm{b}$ & SE b & $\beta$ & $\mathrm{b}$ & SE b & $\beta$ & $\mathrm{b}$ & SE b & B \\
\hline Constant & 7.080 & 1.357 & & 5.049 & 3.213 & & 5.997 & 1.784 & \\
\hline $\begin{array}{l}\text { Conscious Motor } \\
\text { Processing }\end{array}$ & -.023 & .45 & -.047 & -.013 & .077 & -.035 & -.020 & .058 & -.039 \\
\hline $\begin{array}{l}\text { Movement Self- } \\
\text { Consciousness }\end{array}$ & .072 & .037 & $.165^{*}$ & .042 & .053 & .133 & .084 & .051 & .172 \\
\hline Planning & -.067 & .057 & -.129 & .044 & .093 & .094 & -.085 & .072 & -.146 \\
\hline Monitoring & .041 & .102 & .045 & .070 & .166 & .096 & -.005 & .136 & -.005 \\
\hline Effort & .078 & .040 & .179 & -.117 & .076 & -.297 & .133 & .049 & $.285^{* *}$ \\
\hline Self-Efficacy & -.188 & .040 & $-.476^{* * *}$ & -.039 & .082 & -.099 & -.194 & .050 & $-.424^{* * *}$ \\
\hline Reflection & .063 & .057 & .099 & .096 & .118 & .124 & .094 & .070 & .145 \\
\hline Evaluation & -.017 & .034 & -.045 & -.027 & .052 & -.083 & -.022 & .046 & -.054 \\
\hline$R^{2}$ & & .23 & & & .13 & & & .25 & \\
\hline \multicolumn{10}{|c|}{${ }^{*} p<.05,{ }^{* *} p<.01,{ }^{* * *} p<.001$} \\
\hline
\end{tabular}




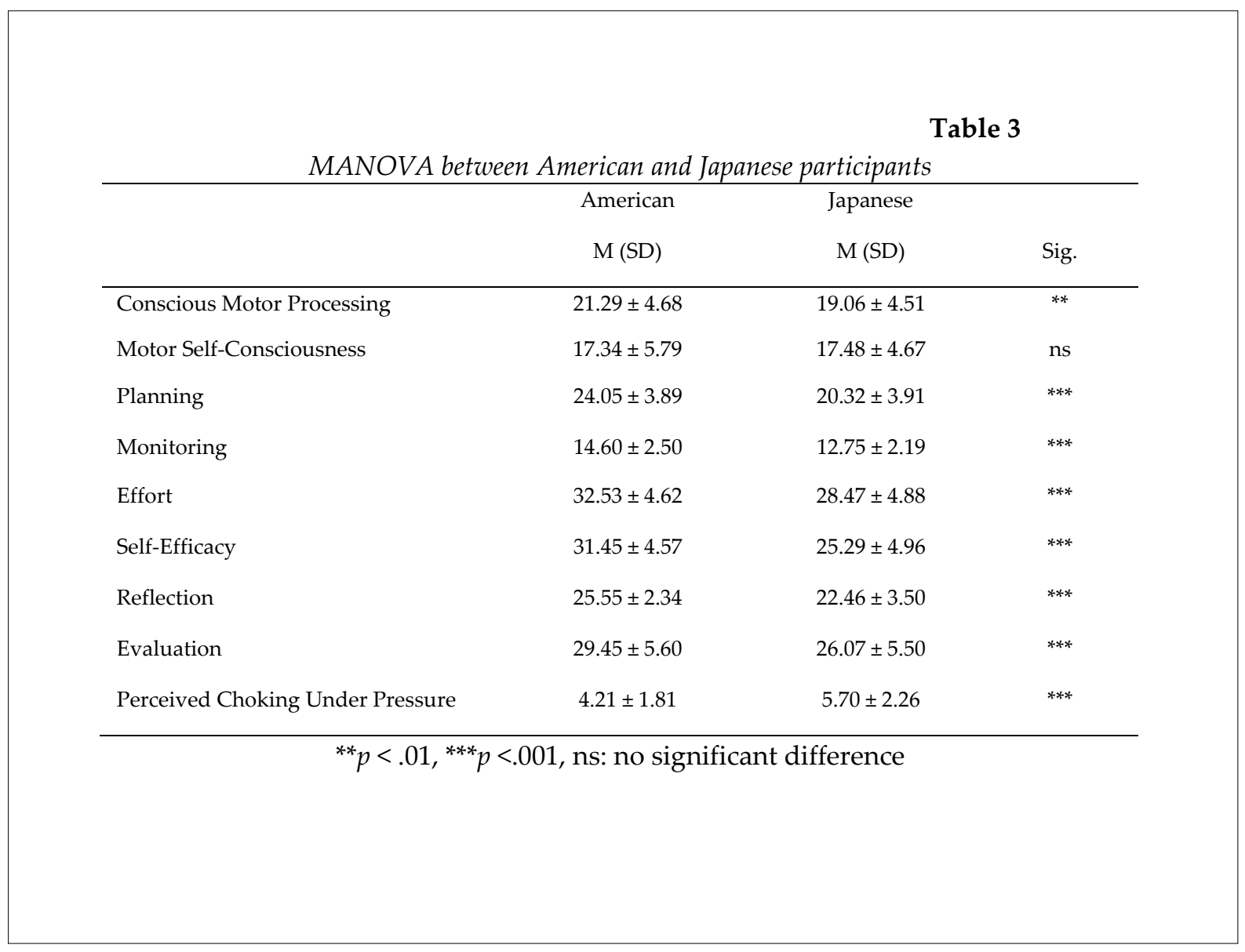

\section{Discussion}

The purpose of the present study was to examine relations among reinvestment, selfregulation, and the perception of choking under pressure among skilled tennis players, specifically from the U.S. and Japan.

\section{Reinvestment and self-regulation}

The conscious motor processing aspect of reinvestment, involving a tendency to consciously control movement, was positively correlated with all of the self-regulation factors that are considered to be critical skills needed by elite/skilled athletes (Cleary et al., 2006; Cleary and Zimmerman, 2001; Jonker et al., 2010, 2011; Kitsantas and Zimmerman, 2002; Toering et al., 2009). Conscious motor processing, as explained, is considered a detrimental factor to performance under pressure (Masters et al., 2005; Masters and Maxwell, 2008). However, it was not associated with perceived choking under pressure in this study, which is in line with previous findings among male collegiate athletes (Iwatsuki and
Wright, 2016). Jackson et al. (2013) revealed that the Reinvestment Scale was associated with a performance decrement in female university hockey and netball players (Study 1); however, the MSRS was not associated with performance failure among female university netball players (Study 2).

In recent studies, Laborde et al. (2015a) found that the MSRS was not related to working memory performance in the high-pressure condition. Moreover, Laborde et al. (2015b) reported that conscious motor processing factor was positively associated with motor imagery ability, challenging the idea that reinvestment can only be considered as detrimental to performance. Although previous literature would suggest that the conscious motor processing factor is detrimental to performance, this study proves that it may also have positive effects on performance.

Jackson et al. (2006) stated that "there is a conceptual difference between explicitly monitoring movement and consciously controlling it (reinvestment) because monitoring 
can occur without conscious control". Jackson et al. (2006) also mentioned that monitoring movement is not sufficient for reinvestment of conscious control, leading to substandard performance. To assess the conscious motor processing factor, five statements such as "I try to think about my movement when I carry them out" and "I reflect about my movement a lot", are used (Masters et al., 2005). Based on these five statements, it seems difficult to discern a difference between monitoring movement and controlling movement. Toner and Moran (2011) revealed that conscious monitoring and conscious control showed differing kinematics of putting strokes as well as putting performance among elite golfers. Future research is needed to better differentiate between monitoring and controlling movement and how two different movements differently or seminally relate to the conscious motor processing factor.

On the other hand, the movement selfconsciousness aspect of reinvestment, which refers to a tendency to be concerned about one's style of movement during motor output, was not correlated with any of the six self-regulation factors and was found to predict one's perception of choking under pressure. These findings support the theory of reinvestment (Masters and Maxwell, 2008), and suggest that conscious thinking about the style of movement (e.g., how to hit a forehand, how to move the arms) during motor output is detrimental to performance under pressure situations.

Three self-regulation factors (i.e., planning, effort, self-efficacy) were negatively correlated with perceived choking under pressure, but only self-efficacy was revealed as a significant predictor of the perception of choking under pressure in the simultaneous entry multiple regression for the combined American and Japanese sample, and the Japanese subsample (Table 2). Therefore, self-efficacy could potentially help protect athletes from choking under pressure. Research supports a negative relationship between self-efficacy and choking under pressure or performance failure (Williams et al., 2002). Additionally, a large number of studies have identified self-efficacy as a strong predictor of performance in various sports (Bandura, 1982, 1997; Clearly and Zimmerman, 2001; Feltz et al., 2008; Kitsantas and Zimmerman,
2002; Martin and Gill, 1991), and as a superior predictor to anxiety and perceived control (Feltz and Lirgg, 2001). Thus, self-efficacy can be considered a critical factor for managing performance under pressure: high performance under pressure is more likely for players high in self-efficacy.

\section{Cultural comparison}

The simultaneous entry multiple regression equation was found to be significant among Japanese players; however, it was not true among American players. Having higher selfefficacy was a critical factor to determine perceived choking under pressure among Japanese players, which supports the relationship between self-efficacy (or confidence) and performing under pressure-filled situations (Beilock, 2010). Ironically, effort was also found to be a predictor; however, the interpretation of the results is difficult: Japanese players with increased perceived effort predicted an increase in perceived choking under pressure. A large sample size is desirable as the number of independent variables increase for predicting a dependent variable (Knofczynski and Mundfrom, 2008). The small sample size for the American players might be an issue for the regression model. This is an exploratory analysis: future research is needed to understand how these variables relate to one's perception of choking under pressure based on specific populations.

In the cross-cultural comparison, American players reported higher levels of selfregulation than Japanese players. This finding makes sense in the light of research indicating that Americans tend to have an independent orientation, whereas Japanese tend to have an interdependent orientation relative to other societies (Kitayama, 2002; Kitayama et al., 2009). Self-regulation, as explained by Zimmerman $(2006,2008)$, is the extent to which individuals are metacognitively, motivationally, and behaviourally proactive in their own learning processes. It is, therefore, not surprising that as a function of their cultural tendency toward independence, American players would be more likely to become proactive learners and develop higher self-regulation skills than Japanese players.

In contrast to the results for selfregulation skills, Japanese players scored higher than American players on perceived choking 
under pressure. Research by Kitayama et al. (1997) offers a potential explanation for this finding. Kitayama et al. (1997) found that in terms of self-evaluation, Japanese individuals were more likely to engage in self-criticism and American individuals were more likely to engage in self-enhancement. Furthermore, as augmented by a growing body of research (Heine et al., 2001; Heine et al., 1999), Kitayama et al. (1997) found that whereas American individuals chose a larger number of success situations than failure situations as relevant to their self-esteem, Japanese individuals chose a larger number of failure situations than success situations. In the sport realm, Peters and Williams (2006) reported that although East Asians used a large proportion of negative self-talk (self-criticism), European Americans used a large proportion of positive self-talk (self-enhancement) when performing a dart-throwing task. Negative self-talk was associated with poor performance for European Americans, but this was not true for East Asians. The higher perception of choking under pressure among Japanese players compared to American players in the present study may reflect the Japanese cultural tendency toward self-criticism relative to the American cultural tendency toward self-enhancement.

\section{Limitations}

Several limitations of the current study should be noted. First, because a cross-sectional research design was used, no causal inferences can be drawn from the results. Second, constructs were assessed with self-report questionnaires, which are susceptible to socially desirable responding (Young and Starkers, 2006). Where possible, an alternate measurement approach should be considered in future research, especially for tennis performance under pressure. Third, with respect to the cross-cultural comparison, it is unclear whether the differences obtained between American and Japanese players reflect actual differences in the constructs measured or cultural differences in responding to self-report measures. As with the previous limitation, alternate measurement approaches may help to address this issue. Therefore, more research is needed to better understand how selfregulation relates to tennis performance (e.g., specific movements and techniques) under pressure, as well as how movement reinvestment factors (conscious motor processing and movement self-consciousness) relate to tennis performance under pressure within various cultures. Investigation of the cognitive processes underlying monitoring and controlling performance would be a worthy topic for future study.

\section{Conclusions}

In summary, this research explored relations among reinvestment, self-regulation, and perceived tendency to choke under pressure. The research findings indicated that conscious motor processing might be beneficial to tennis players; challenging the idea that reinvestment can only be considered as detrimental to performance. In addition, two factors, movement self-consciousness and self-efficacy, were found to predict perceived choking under pressure. Confidence in the performer's ability to execute during pressure situations is a key factor for coaches and players to consider. Performing outside conscious awareness, as opposed to conscious thinking about the style of movement, may facilitate successful outcomes. It may be useful for coaches to be aware that some players are less likely to self-regulate their internal thoughts relative to other players.

\section{Acknowledgements}

This study was supported by the International Tennis Federation (ITF) Research Grant. The authors thank all players, coaches, and universities/colleges for their enthusiastic participation.

\section{References}

Bandura A. Self-efficacy mechanism in human agency. Am Psychol, 1982; 37: 122-147 
Bandura A. Self-efficacy: The exercise of control. New York: Freeman; 1997

Baumeister R. Choking under pressure: Self-consciousness and paradoxical effects of incentives on skillful performance. J Pers Soc Psychol, 1984; 46: 610-620

Beilock S. Choke: What the secrets of the brain reveal about getting it right when you have to. New York: Free Press; 2010

Beilock S, Carr T. On the fragility of skilled performance: What governs choking under pressure? J Exp Psychol Gen, 2001; 130: 701-725

Cleary T, Zimmerman B. Self-regulation differences during athletic practice by experts, non-experts, and novices. J Appl Sport Psychol, 2001; 13: 185-201

Cleary T, Zimmerman B, Keating T. Training physical education students to self-regulate during basketball free throw practice. Res Q Exer Sport, 2006; 77: 151-262

Feltz D, Lirgg C. Self-efficacy beliefs of athletes, team, and coaches. In RN Singer, HA Hausenblas, C Janelle (Eds.), Handbook of sport psychology. New York: Wiley, 340-361; 2001

Feltz DL, Short SE, Sullivan PJ. Self-efficacy in sport. Champaign. IL: Human Kinetics, 340-361; 2008

Hong E, O'Neil Jr H. Construct validation of a trait self-regulation model. Int J Psychol, 2001; 36: 186-194

Hayashi C, Weiss M. A cross-cultural analysis of achievement motivation in Anglo-American and Japanese marathon runners. Int J Sport Psychol, 1994; 25: 187-202

Heine S, Kitayama S, Lehman D, Tanaka T, Ide E, Leung C, Matsumoto H. Divergent consequences of success and failure in Japan and North America: An investigation of self-improving motivations and malleable selves. J Pers Soc Psychol, 2001; 81: 599-615

Heine S, Lehman D, Markus H, Kitayama S. Is there a universal need for positive self-regard? Psychol Rev, 1999; 106: 766-794

Howard B, McGee S, Shia R, Hong N. Metacognitive self-regulation and problem-solving expanding the theory base through factor analysis. Paper presented at the Annual Meeting of the AERA, New Orleans, LA; 2000

Isogai $\mathrm{H}$, Brewer B, Cornelius A, Etnier J, Tokunaga M. A cross-cultural analysis of goal orientation in American and Japanese physical education students. Int J Sport Psychol, 2003; 34: 80-93

Iwatsuki T, Wright P. Relationship among movement reinvestment, decision-making reinvestment, and perceived choking under pressure. Int J Coach Sci, 2016; 10(1): 25-35

Jackson R, Ashford K, Norsworthy G. Attentional focus, dispositional reinvestment, and skilled motor performance under pressure. J Sport Exerc Psychol, 2006; 28: 49-68

Jackson R, Kinrade N, Hicks T, Wills R. Individual propensity for reinvestment: Field-based evidence for the predictive validity of three scales. Int J Sport Psychol, 2013; 44: 331-350

Jonker L, Elferink-Gemser M, Visscher C. Differences in self-regulatory skills among talented athletes: The significance of competitive level and type of sport. J Sport Sci, 2010; 28: 901-908

Jonker L, Elferink-Gemser M, Visscher C. The role of self-regulatory skills in sport and academic performances of elite youth athletes. Talent Dev Excellence, 2011; 3: 263-275

Kinrade N, Jackson R, Ashford K. Dispositional reinvestment and skill failure in cognitive and motor tasks. Psychol Sport Exerc, 2010; 11: 312-319

Kitayama S. Cultural psychology of the self: A renewed look at independence and interdependence. In C Hofsten, Backman (Eds.). Psychology at the turn of the millennium, Florence, KY: Taylor \& Francis/Routledge, 305-322; 2002

Kitayama S, Markus H, Matsumoto H, Norasakkunkit V. Individual and collective processes in the construction of the self: Self-enhancement in the United States and self-criticism in Japan. J Pers Soc Psychol, 1997; 72: 1245-1267

Kitayama S, Park H, Sevincer A, Karasawa M. A cultural task analysis of implicit independence: Comparing North America, Western Europe, and East Asia. J Pers Soc Psychol, 2009; 97: 236-255

Kitsantas A, Zimmerman B. Comparing self-regulatory processes among novice, non-experts, and expert volleyball players: A micro analytic study. J Appl Sport Psychol, 2002; 14: 91-105

Knofczynski GT, Mundfrom D. Sample sizes when using multiple linear regression for prediction. Edu Psychol Meas, 2008; 68: 431-442

Laborde S, Furley P, Schempp C. The relationship between working memory, reinvestment, and heart rate 
variability. Physiol Behav, 2015a; 139: 430-436

Laborde S, Musculus L, Kalicinski M, Klampfl M, Kinrade N, Lobinger B. Reinvestment: Examining convergent, discriminant, and criterion validity using psychometric and behavioral measures. Pers Individ Differ, 2015b; 78: 77-87

Masters R. Knowledge, knerves and know-how: The role of explicit versus implicit knowledge in the breakdown of a complex motor skill under pressure. Brit J Psychol, 1992; 83: 343-358

Masters R, Eves F, Maxwell J. Development of a movement specific reinvestment scale. In T Morris, P Terry, S Gordon, S Hanrahan, L Ievleva, G Kolt, P Tremayne (Eds.), Proceedings of the ISSP 11th World Congress of Sport Psychol, Sydney, Australia: Int Soc Sport Psychol, 14-19; 2005

Masters R, Maxwell J. The theory of reinvestment. Int Rev Sport Exerc Psychol, 2008; 1: 160-183

Masters R, Maxwell J, Eves F. From novice to no know-how: A longitudinal study of implicit motor learning. J Sports Sci, 2000; 18: 111-120

Masters R, Polman R, Hammond N. Reinvestment: A dimension of personality implicated in skill breakdown under pressure. Pers Individ Differ, 1993; 14: 655-666

Malhotra N, Poolton J, Wilson M, Fan J, Masters R. Conscious motor processing and movement selfconsciousness: Two dimensions of personality that influence laparoscopic training. J Surg Educ, 2014; 71: 798-804

Martin J, Gill D. The relationship among competitive orientation, sport confidence, self-efficacy, anxiety, and performance. J Sport Exerc Psychol, 1991; 13: 149-159

Matheson H, Brewer B, Van Raalte J, Andersen M. Athletic identity of national level badminton players: A cross-cultural analysis. In T Reilly, M Hughes, A Lees (Eds.), Science and racket sports. London: E. \& F. N. Spon, 228-231; 1994

Nota L, Soresi S, Zimmerman B. Self-regulation and academic achievement and resilience: A longitudinal study. Int J Educ Res, 2004; 41: 198-215

Peltier J, Hay A, Drago W. Reflecting on self-regulation: Scale extension and a comparison of undergraduate business students in the United Kingdom. J Mark Educ, 2006; 28: 5-16

Peters H, Williams J. Moving cultural background to the foreground: An investigation of self-talk, performance, and persistence following feedback. J Appl Sport Psychol, 2006; 13: 240-253

Toering T, Elferink-Gemser M, Jordet G, Visscher C. Self-regulation and performance level of elite and nonelite youth soccer players. J Sport Sci, 2009; 27: 1509-1517

Toner J, Moran A. Enhancing performance proficiency at the expert level: Considering the role of "continuous improvement" in expert athletes. Frontiers in Psychol, 2015; 1: 1-5

Williams A, Vickers J, Rodrigues S. The effects of anxiety on visual search, movement kinematics, and performance in table tennis: A test of Eysenck and Calvo's processing efficiency theory. J Sport Exer Psychol, 2002; 24: 438-455

Young B, Starkers J. Measuring outcomes of swimmers' non-regulation during practice: Relationships between self-report, coaches' judgement, and video-observation. Int J Sports Sci Coach, 2006; 1: 131-148

Zimmerman B. Development and adaptation of expertise: The role of self-regulatory processes and beliefs. In KA Ericson, N Charness, PJ Feltovich, RR Hoffman (Eds.), The Cambridge handbook of expertise and expert performance. New York, NY: Cambridge University Press, 705-722; 2006

Zimmerman B. Investigating self-regulation and motivation: Historical background, methodological developments, and future prospects. Am Educ Res J, 2008; 45: 166-183

\section{Corresponding author:}

\section{Takehiro Iwatsuki}

Department of Kinesiology, Pennsylvania State University, Altoona College; 3000 Ivyside Park, Altoona, Pennsylvania 16601

E-mail: tui36@psu.edu 